DOI: 10.20472/IAC.2017.034.008

TOVA BAND-WINTERSTEIN

University of Haifa, Department of Gerontology, Israel

OFFER E. EDELSTEIN

2. Ben-Gurion University of the Negev, The Spitzer Department of Social Work, Israel

YAACOV G. BACHNER

Ben-Gurion University of the Negev, Department of Public Health, Israel

\title{
DETERMINANTS OF DEPRESSIVE SYMPTOMATOLOGY IN CAREGIVERS OF FRAIL OLDER-ADULTS: THE CASE OF ULTRA-ORTHODOX JEWISH COMMUNITY
}

\begin{abstract}
:
Depression is the most frequent negative health outcome among informal caregivers. The aims of the current study were (i) to assess the level of depression, (ii) to explore associations between care recipients' characteristics, caregivers' characteristics, situational factors and depression among Ultra-Orthodox Jewish (UOJ) caregivers. A total of 112 (44 men and 68 women) UOJ primary caregivers of frail older-adults were interviewed face-to-face in their homes, using valid and reliable measures. Participants reported a notable depressive symptomatology. Three variables emerged as significant predictors of caregiver depression: higher external control (chance), being a spouse, and lower levels of social support. External locus of control, being a spouse, and social support are highly important factors for explaining depression among UOJ caregivers. Resources should be allocated to target spousal caregivers with lower levels of social support and a greater sense of external locus of control in order to alleviate their depressive symptomatology.
\end{abstract}

\section{Keywords:}

Minorities, Ultra-Orthodox Jews, depressive symptomatology , caregiving, older adults 